\title{
Bir Üniversite Hastanesindeki Sağlık Çalışanlarında Ramazan Orucunun Ruh Sağlı̆̆ Üzerine Etkileri
}

\author{
The Effects of Ramadan Fasting on Mental Health in Health Professionals in a \\ University Hospital
}

\author{
Fatma Kartal $^{1}$, Sümeyye Demirbay², Burak Mete ${ }^{3}$, Cemal Özcan $^{4}$, Süheyla Ünal ${ }^{2}$ \\ ${ }^{1}$ Malatya Eğitim ve Araştırma Hastanesi Psikiyatri Bölümü, Malatya \\ ${ }^{2}$ İnönü Üniversitesi Tip Fakültesi Psikiyatri Anabilim Dal, Malatya \\ ${ }^{3}$ Çukurova Üniversitesi Tip Fakültesi Halk Sağlığı Anabilim Dalı, Adana \\ ${ }^{4}$ İnönü Üniversitesi Tip Fakültesi Nöroloji Anabilim Dal, Malatya \\ ${ }^{5}$ İnönü Üniversitesi Tip Fakültesi Psikiyatri Anabilim Dalı, Malatya
}

Yazışma Adresi / Correspondence:
Fatma Kartal
Özalper Mah Turgut Özal Bulvarı No:4, 44090 Yeşilyurt/Malatya
T: +90505 $6616689 \quad$ E-mail : fatonkartal@icloud.com
Geliş Tarihi / Received : 16.10.2020 Kabul Tarihi / Accepte: 03.04.2021
Orcid :
Fatma Kartal https://orcid.org/0000-0002-5379-0021
Sümeyye Demirbay https://orcid.org/0000-0003-0643-3619
Burak Mete https://orcid.org/0000-0002-0780-6176
Cemal Özcan https://orcid.org/0000-0002-6759-7556
Süheyla Ünal https://orcid.org/0000-0003-3266-6256
( Sakarya Tip Dergisi / Sakarya Med J 2021, 11(2):337-346 ) DoI: 10.31832/smj.811781

( Sakarya Tip Dergisi / Sakarya Med J 2021, 11(2):337-346) DOI: 10.31832/smj.811781

\footnotetext{
$\ddot{O} z$

Amaç Ramazan orucunun sağılklı bireylerde psikiyatrik belirti düzeyine etkisine ilişkin alan yazınındaki bilgilerin çelişkili olduğu bildirilmiștir. Ramazan orucu srrasında gün içerisinde kayı ve öfke gibi psikiyatrik belirtilerde artış olabileceğini, bu nedenle orucun psikiyatrik belirtilere olumlu yönde etkisinin bir ayllk süre içerisinde gelişen muhtemel uyumsal mekanizmaların devreye girmesiyle olușabileceğini varsaydık. Bu nedenle çalışmamızda Ramazan ayı öncesi ve sonrasında genç eriṣkin sağllk çalşanlarında genel psikiyatrik belirtileri değerlendirdik.

Gereç ve İnönü Üniversitesi Tip Fakültesi, Turgut Özal Tip Merkezỉnde görev alan, 77 genç erişkin sağlık çalışanına, 2019 yllı Ramazan ayından bir hafta önce, Sosyodemografik

Yöntem Veri Formu, Genel Sağlık Anketi (GSA) ve Kısa Semptom Envanteri (KSE) doldurtulmuștur. Aynı katılımcilara Ramazan ayından bir hafta sonra GSA ve KSE tekrar doldurulmuștur. Verilerin analizinde SPSS 22 istatistiksel paket program kullanılmıștır.

Bulgular Çalışmamıza 37’si (\%48,1) erkek, 40’’ (\%52,0) kadın 77 katılımıı dahil edilmiștir. Cinsiyetlere göre ölçeklerden elde edilen değerlere bakıldığında kadın katılımcılarda Ramazan ayı öncesi ve sonrası KSE ve GSA’ da sıklık ve ortalama değeler açısından istatistiksel olarak anlamlı farklılık olmadı̆̆ı tespit edilmiștir. Erkekler katılımclarda Ramazan öncesine göre sonrasında GSA' nin hem sıklık hem de ortalama puanları, KSE’ nin alt ölçeklerinden anksiyete, paranoid düşünce ve psikotizm sıklı̆̆ı ve kişiler arası duyarllık, depresyon, paranoid düşünce ve KSE global ölçeklerinin ortalama puanları anlamlı derecede düşük saptanmıştır. Erkek katılımcılarda GSA ve KSE’ de kişiler arası duyarlılık, depresyon, paranoid düşünce, psikotizm alt ölçekleri ve tüm global indekslerdeki değişime ramazan orucunun etki büyüklüğünün küçük derecede olduğu tespit edilmiştir.

Sonuç Ramazan orucu sonrası kadınlarda psikiyatrik belirtilerde anlamlı değişiklik gözlenmezken, erkeklerde bazı psikiyatrik belirtilerde iyileşme olması, orucun psikiyatik belirtilerdeki etkisinin cinsiyete göre farkllılk gösterebileceğini düşündürmektedir.

Anahtar Oruç; Depresyon; Anksiyete; Stres; Psikoloji

Objective It was reported in the literature that the information on the effect of Ramadan fasting on psychiatric symptoms in healthy individuals was contradictory. We hypothesized that there might be an increase in psychiatric symptoms such as anxiety and anger during Ramadan fasting; thus, the positive impact of fasting on psychiatric symptoms could be due to the activation of possible adaptive mechanisms that develop during this month. Therefore, the present study aimed to analyze general psychiatric symptoms observed in young adult healthcare professionals before and after Ramadan.

Materials One week before Ramadan, 77 young adult healthcare professionals employed at İnönü University, Faculty of Medicine, Turgut Özal Medical Center completed the Sociodemographic Data and methods Form, General Health Questionnaire (GHQ) and the Brief Symptom Inventory (BSI). The same participants completed the GHQ and BSI again one week after Ramadan. SPSS 22 statistics software was employed to analyze the study data.

Results Thirty-seven (48,1\%) male, 40 (52,0\%) female, a total of 77 participants were included in the study. The analysis of the scale scores based on gender demonstrated that there was no statistically significant difference between the frequencies and mean BSI and GHQ scores before and after Ramadan in female participants. In male participants, there were significant decreases in the frequency and mean GHQ scores, the frequencies of BSI subscales, namely anxiety, paranoid and psychotic ideation, and mean interpersonal sensitivity, depression, paranoid ideation and BSI global scale scores in male participants after Ramadan. It was determined that the effect size of Ramadan fasting on changes in interpersonal sensitivity, depression, paranoid ideation, psychotic ideation sub-scale and all global GHQ and BSI scores was small in male participants.

Conclusion While psychiatric symptoms did not change significantly among women after Ramadan fasting, certain psychiatric symptoms improved among men, suggesting that the impact of fasting on psychiatric symptoms could differ by gender.

Keywords Fasting; Depression; Anxiety; Stress; Psychology.
} 


\section{GIIRIș}

Ramazan orucu, 'dini kurallara göre belirlenmiş ibadeti yerine getirme niyetiyle, tan yerinin ağarmasından güneşin batışına kadar olan süre içerisinde, bireyin yeme, içme ve cinsel ilişkiden uzak durması' olarak tanımlanır. ${ }^{1}$ Yıl içinde denk geldiği zamana ve coğrafi konuma göre Ramazan ayı boyunca tutulan oruç süresi 10-20 saat arası değişkenlik gösterir. ${ }^{2}$ Ramazan orucunun hem metabolizma hem de sirkadiyen ritm üzerinde pek çok değişikliğe sebep olduğu bilinmektedir. Özellikle azalan gece uykusu veya gündüz uyku süresindeki artış ile ilişkili olarak başta yorgunluk ve dikkat olmak üzere psikolojik durum üzerine etki edebileceği birçok araştırmada incelenmiştir. ${ }^{3}$ Ancak literatürde Ramazan orucunun sağlıklı bireylerde psikiyatrik belirti düzeyine etkisi ile ilişkili çelişkili sonuçlar olduğu bildirilmektedir. ${ }^{4}$ Ramazan orucu tutanlarda özellikle öğleden sonraki vakitlerde stres, kaygı ve öfkenin artmış olduğuna dikkat çekilmiştir. ${ }^{5}$ Bazı çalışmalarda da Ramazan başlangıcı ile karşılaştırıldı̆̆ında sonlarına doğru, depresif belirti ve stres seviyelerinde azalma gözlendiği bildirilmiştir. ${ }^{6}$

İslami kültürdeki Ramazan orucuyla benzer özellikler taşıyan ve son yıllarda birçok araştırmaya konu olan aralıklı açlık diyeti; belirlenmiş zaman döngülerinde açlık ve yeme periyotlarını içeren bir diyet türüdür. Alternatif-günlük açlık, periyodik açlık ve günlük kısıtlamalı beslenme olarak 3 çeşittir. ${ }^{7}$ Dini orucun bir aralıklı açlık diyeti çeşidi olan periyodik açlık içerisinde yer aldığı kabul edilmektedir. ${ }^{8}$ Aralıklı açlık diyetinin kardiyo-vasküler hastalık ve kanser için risk faktörlerinin azaltılması, enfeksiyonlarda inflamatuvar yanıtın düzenlenmesi ve nörodejeneratif bozuklukların iyileştirilmesi gibi fiziksel sağlık ile ilişkili olumlu etkileri olduğu bildirilmektedir.,10 Ayrıca aralıklı açlık diyetinin, erken dönemde (2-7 gün) duygu durum, uyanıklık ve huzur duygusunda iyileştirici etkisi olduğu bildirilmekle birlikte duygu durum üzerine kalıcı etkilerinin belirlenmesinin önemli olduğu vurgulanmıştır. ${ }^{11}$ Yeme sıklığında azalmanın ruh sağlı̆̆ına iyileştirici etkide bulunabileceği düşünülmektedir. ${ }^{11}$ Aralıklı açlığın hem insan hem de hayvanlarda distres olmaktan öte, östres etkeni olabileceği varsayılmaktadır. ${ }^{12}$ Bu durum, yüksek dozlarda zarar verici etkisi olan kimyasal madde veya çevresel faktörlere, düşük dozda maruz kalındığında organizma üzerinde uyarlanabilir yararlı etkinin ortaya çıktığı süreç olarak tanımlanan hormeozise benzetilmektedir. ${ }^{26}$ Oruç ile birlikte düşük kalori alımının, düşük yoğunluklu biyolojik strese neden olarak organizmanın savunma tepkilerini devreye soktuğu ve dayanıklılığ 1 arttırdığı çıkarımı yapılmaktadır. ${ }^{13,14}$ Uyarlanabilir kronik stresin organizma ve çevresi arasında bir uyum süreci olduğu göz önüne alındığında, Müslümanların bir ay süre ile gıda alımını kısıtladığ 1 diürnal aralıklı oruç diyetinin bir örneği olarak kabul edilen Ramazan orucu, bu alandaki araştırmalar için önemli bir firsat oluşturmaktadır. ${ }^{12}$ Bu kapsamda Ramazan orucunun, sağlıklı erişkinlerde psikiyatrik durumlarla ilişkisini değerlendiren çalışmalara ihtiyaç duyulduğu bildirilmiştir. ${ }^{3,12}$

İlgili alan yazınındaki bilgiler doğrultusunda çalışmamızda, Ramazan orucu sırasında gün içerisinde anksiyete ve öfke gibi belirtilerde artışın olabileceği, bu nedenle orucun psikiyatrik belirtilere etkisinin bir aylık süre içerisinde gelişen muhtemel adaptif mekanizmaların devreye girmesinin sonunda ortaya çıkabileceğini Ramazan ayı öncesine göre Ramazan ayı sonrasında değerlendirdiğimiz ruhsal belirtilerin şiddetinde azalma olabileceğini varsaydık. Sağlıklı bireylerdeki psikolojik belirtilerdeki değişimde Ramazan orucunun etkisine ilişkin tespit edeceğimiz sonuçların literatüre katkı sağlayacağını düşünmekteyiz.

\section{GEREÇ ve YÖNTEMLER}

Örneklem grubumuzu belirlerken, sağlık çalışanlarını hem vardiya/nöbet usulü çalışmaları nedeniyle Ramazan ayı dışında da gece uykusuzluğuna rağmen günlük hayatlarına devam ettikleri için hem de Ramazan ayında gün içerisinde aktif olarak çalıştıkları için normal popülasyona göre Ramazan ayında oruç tuttukları dönem boyunca sirkadyen ritm değişikliğinden daha az etkileneceğini varsaydık. Bu nedenle araştırmamızın örneklem grubunu bilinen fiziksel hastalığı olmayan genç erişkin sağlık çalışanları 
olarak belirledik.

Araştırmamızın etik kurul onayı T.C İnönü Üniversitesi Bilimsel Araştırma ve Yayın Etiği Kurulu’nun 30.07.2019 tarihli oturumundan, 2019/246 araştırma protokol numarası ile alınmıştır. Çalışma Helsinki Bildirgesine uygun olarak yürütülmüştür.

Çalışma İnönü Üniversitesi Turgut Özal Tıp Merkezi’nde çalışan, genç erişkin (25-45 yaş) sağlık çalışanlarında 2019 yılı Ramazan ayından bir hafta önce ve Ramazan ayından bir hafta sonra gerçekleştirildi. Power analizi sonucuna göre ( $\alpha=0,05$ 1- $ß$ (güç): 0.80 alındığında oruç tutanlarda çalışmaya en az 63 katılımcı alınması gerektiği hesaplandı. Çalışmaya dahil edilme kriterleri: 18-45 yaş arasında, sağlık çalışanı olmak, psikiyatri uzmanının değerlendirmesine göre herhangi bir psikiyatrik bir bozukluk tanıs1nı karşılamıyor olmak, kronik fiziksel bir hastalık tanısına, kafa içi yer kaplayan lezyona, nörolojik hastalığa veya uygulanan ölçekleri okuyup anlamaya engel teşkil edecek herhangi bir mental hastalığa sahip olmamak olarak belirlendi.

\section{İșlem}

Çalışmamızın Etik kurul onayı alındıktan sonra araştırmaya dahil edilme kriterlerine uyan katılımcılar psikiyatri uzmanı tarafından değerlendirildi ve DSM-5’ e göre herhangi bir psikiyatrik bozukluk tanısını karşılamadıkları belirlendi. ${ }^{15}$ Katılımcıların önceki anamnez ve tıbbi kayıtları incelenerek geçmiş veya şu anki hali ile ruhsal ve fiziksel hastalık tanısı bulunmayan katılımcılara, Ramazan ayından bir hafta önce Sosyodemografik Veri Formu psikiyatri uzmanı tarafından, Genel Sağlık Anketi (GSA) ve Kısa Semptom Envanteri (KSE) katılımcilar tarafından dolduruldu. Katılımcılar Ramazan ayı bittikten bir hafta sonra psikiyatri uzmanı tarafından tekrar değerlendirildi ve DSM-5' e göre herhangi bir psikiyatrik bozukluk tanısını karşılamayan katılımcılar tarafından GSA ve KSE tekrar dolduruldu.
Toplamda 90 katılımcıya ölçekler uygulandı. Ramazan ayından bir hafta öncesinde uygulanan ölçeklerdeki maddeleri eksik dolduran 6 katılımcı ve Ramazan ayından bir hafta sonrasında izin döneminde oldukları için tekrar ölçek uygulanmasına çağırılamayan 7 katılımcı çalışmadan çıkarıldı. Sonuç olarak 77 katılımcı ile çalışmanın örneklemi tamamland.

\section{Genel Sağlık Anketi-12 (GSA-12)}

Özellikle birinci basamakta ruhsal rahatsızlığı ayırt etmek üzere Goldberg (1972) tarafından geliştirilen bir öz bildirim ölçeğidir. ${ }^{16} 60$ soruluk formunun takiben geliştirilen 30, 28, 12 soruluk kısa formları da aynı şekilde güvenilir bulunmuştur. Bu çalışmada kullanılan GSA, 12 soru içermektedir. Her soru (hiçbir zaman), (her zamanki kadar) , (her zamankinden sık), (çok sık) olmak üzere 4 şıłtan oluşmaktadır. Yanıtlar likert (0-1-2-3) ölçeği şeklinde derecelendirilir. Ölçeğin Türkçe geçerlik ve güvenilirlik çalışması Kılıç (1996) tarafından yapılmıştır. ${ }^{17}$ Cronbach alfa değeri 0.78 'dir.

\section{Kisa Semptom Envanteri (KSE)}

Çeşitli psikolojik belirtileri taramak amacıyla kullanılan, ergen ve yetişkinlere uygulanan bir öz bildirim ölçeğidir. KSE, Derogatis (1992) tarafından çeşitli psikolojik belirtileri taramak amacıyla geliştirilmiştir. ${ }^{18}$ Ölçeği dolduran bireyler 53 maddeden oluşan psikolojik semptomları kendilerine uyan şiddete göre hiç yok=0 ile çok fazla var=4 arasında değişen 5 kategoride işaretlerler. Ölçekten alınan toplam puanların yüksekliği bireyin belirtilerinin şiddetini göstermektedir. KSE, somatizasyon, obsesif kompülsif belirtiler, kişilerarası duyarlılık, depresyon, anksiyete, hostilite, fobik anksiyete, paranoid düşünceler, psikotizm ve ek maddeler olmak üzere 10 alt ölçek ve Rahatsılılı Ciddiyeti İndeksi, Belirti Toplamı İndeksi ve Global Semptom İndeksi olmak üzere 3 global indeksten oluşur. KSE’nin Türkçe geçerlilik ve güvenilirlik çalışması Şahin ve Durak (1994) tarafından yapılmıştır. Çalışmanın cronbach alfa değeri; 0, 96'dır. ${ }^{19}$ 


\section{İstatistiksel analiz}

Verilerin analizinde SPSS 22 programı kullanılmıştır. Analizlerde Mc Nemar testi, $t$ testi, paired t testi, Wilcoxon testi, Mann Whitney U testi, Ki-kare testi kullanılmıştır. Etki değerleri effect size calculator ile hesaplanmıștır. Genel olarak, 'Cohen d' değerinin yorumlanması: $\mathrm{d} \geq 1$ çok büyük etki, 0.8 büyük etki, 0.5 orta etki, 0.2 küçük etki olarak kabul edilmiştir. $\mathrm{p}<0,05$ önemli kabul edilmiştir.

\section{BULGULAR}

Çalışmamıza 37’si $(\% 48,1)$ erkek, 40’ı $(\% 52,0)$ kadın toplam 77 sağlıklı gönüllü sağlık personeli katılmıştır. Tüm katılımcıların yaş ortalaması 30,6 $\pm 5,6$ 'dir (min: 21, max: 45). Kadınların yaş ortalaması $29,6 \pm 4,9$, erkeklerin yaş ortalaması 31,7 $\pm 6,1^{\prime}$ dır. Cinsiyet açısından örneklemimizin istatistiksel olarak anlamlı farklılık göstermediği tespit edilmiştir. Katılımcıların, GSA' dan ve KSE' de elde edilen puanlarından kesme değerinin üzerinde olan katılımcıların sıklığı Tablo 1'de verilmiştir.

Ramazan öncesine göre Ramazan sonrasinda paranoid düşünce (\%23,4'den \%14,3'e) ve psikotizm belirtilerindeki sıklıkta (\%28,6'dan \%19,5'e) istatistiksel olarak anlamlı azalma olduğu saptanmıştır (Tablo 1).

GSA ve KSE den aldıkları ortalama puanların Ramazan ayı öncesi ve sonrasına karşılaştırılmasına ait veriler Tablo 2'de sunulmuştur. Katılımcıların Ramazan sonrası Ramazan öncesine göre KSE alt ölçeklerinden obsesif kompulsif belirti ve paranoid düşünce ortalama puanlarında ve KSE global indekslerinden Rahatsızlık Ciddiyeti ve Semptom Rahatsızlık İndeksi ortalama puanlarında istatistiksel olarak anlamlı azalma olduğu saptandı. Ramazan ayının paranoid düşünce ve Semptom Rahatsılzlk İndeksine küçük düzeyde etki gösterdiği bulundu.

GSA ve KSE alt ölçeklerinin kesme değerine göre cinsiyetler arasında karşılaştırılmasına ait veriler Tablo 3'de verilmiştir. Erkek katılımcılarda Ramazan öncesine göre Ramazan sonrası GSA ve KSE alt ölçeklerinden anksiye- te, paranoid düşünce ve psikotizm sıklığında istatistiksel olarak anlamlı azalma saptanmıştır. Ramazan öncesi GSA kesme değeri üzerinde olan erkek katılımcıların oranı \%56,8, Ramazan sonrası \%40,5'dir. Erkeklerde Ramazan öncesi; anksiyete $\% 40,5$, paranoid düşünce $\% 35,1$ psikotizm \% 43,2 oranında saptanmıștır. Ramazan sonrası bu oranlar sırası ile \%24,3, \%16,2 ve \%24,3 tespit edilmiştir. Kadın katılımcılarda Ramazan ayı öncesi ve sonrası KSE nin hiçbir alt parametresinde ve GSA' da sıklık açısından istatistiksel olarak anlamlı farklılık olmadığı tespit edilmiştir.

Ramazan öncesi obsesif kompulsif belirti, kişiler arası duyarllık, hostilite, fobik anksiyete, paranoid düşünce, psikotizm, ek maddeler ve Rahatsızlık Ciddiyeti İndeksi ortalama puanları erkek katılımcılarda anlamlı olarak daha yüksek tespit edilmiştir. Ramazan sonrasında ise kadınlara göre erkeklerde istatistiksel olarak anlamlı düzeyde yükseklik kişiler arası duyarlılık, fobik anksiyete ve ek maddelerin ortalama puanlarında tespit edilmiştir (Tablo4).

Cinsiyete Göre Ramazan öncesi ve Ramazan sonrası GSA ve KSE ortalama puanları ve değişim ile ilişkili veriler Tablo 5'de sunulmuştur. Erkeklerde KSE alt ölçeklerinden kişiler arası duyarlılık, depresyon, paranoid düşünce ve KSE global ölçekleri ve GSA ortalama puanları Ramazan öncesine göre Ramazan ayı sonrasında anlamlı derecede düşük saptanmıştır. GSA, KSE' de kişiler arası duyarlılık, depresyon, paranoid düşünce, psikotizm alt ölçekleri ve tüm global indekslerdeki değişime Ramazan orucunun etki büyüklüğünün küçük derecede olduğu tespit edilmiştir. Kadın katılımcılarda Ramazan ayı öncesi ve sonrasında GSA ve KSE ortalama puanları arasında istatistiksel olarak anlamlı farklılık olmadığı, Ramazan orucunun KSE Semptom rahatsızlık İndeksine etki büyüklüğünün küçük düzeyde olduğu saptanmıștır.

\section{TARTIŞMA}

Çalışmamızda genç erişkin sağlık çalışanlarında Ramazan 
Sakarya Tip Dergisi 2021;11(2):337-346

KARTAL ve Ark., Orucun Ruh Sağlığı Ưzerine Etkileri

Tablo 1: Tüm Katılımcıların Ramazan Öncesi ve Sonrası GSA ve KSE’den aldıkları puanlara göre kesme değerinin üzerinde olanların dağılımı ve oranı

\begin{tabular}{|l|c|c|c|}
\hline & $\begin{array}{c}\text { Ramazan Öncesi } \\
\mathrm{n}(\%)\end{array}$ & $\begin{array}{c}\text { Ramazan Sonrası } \\
\mathrm{n}(\%)\end{array}$ & 0.263 \\
\hline Genel Sağlık Anketi & $43(\% 55.8)$ & $37(\% 48.1)$ & 0.549 \\
\hline Somatizasyon & $22(\% 28.6)$ & $22(\% 28.6)$ & 0.754 \\
\hline Obsesif-kompulsif belirtiler & $18(\% 23.4)$ & $15(\% 19.5)$ & 1.000 \\
\hline Kişiler arası duyarlılık & $18(\% 23.4)$ & $16(\% 20.8)$ & 0.267 \\
\hline Depresyon & $17(\% 22.1)$ & $19(\% 24.7)$ & 0.774 \\
\hline Anksiyete & $24(\% 31.2)$ & $18(\% 23.4)$ & 0.180 \\
\hline Hostilite & $20(\% 26)$ & $19(\% 24.7)$ & $\mathbf{0 . 0 3 9}$ \\
\hline Fobik anksiyete & $25(\% 32.5)$ & $11(\% 14.3)$ & $\mathbf{0 . 0 3 9}$ \\
\hline Paranoid düşünce & $18(\% 23.4)$ & $15(\% 19.5)$ & 0.549 \\
\hline Psikotizm & $22(\% 28.6)$ & $16(\% 20.8)$ & - \\
\hline Ek maddeler & $19(\% 24.7)$ & 0 & 0.453 \\
\hline Rahatsılık Ciddiyeti İndeksi & 0 & $20(\% 26)$ & - \\
\hline Belirti Toplamı & $23(\% 29)$ & 0 & \\
\hline Semptom rahatsızlık indeksi & $3(\% 3.9)$ & & \\
\hline Ki-kare testi & & & \\
\hline
\end{tabular}

Tablo 2: Tüm Katılımcıların Ramazan Öncesi ve Ramazan Sonrası GSA ve KSE Ortalama Puanları

\begin{tabular}{|l|c|c|c|c|}
\hline & $\begin{array}{c}\text { Ramazan Öncesi } \\
\text { Ort } \pm(S S)\end{array}$ & $\begin{array}{c}\text { Ramazan Sonrası } \\
\text { Ort } \pm(S S)\end{array}$ & E.S(d) \\
\hline Genel Sağlık Anketi & $1.77 \pm 2.35$ & $1.56 \pm 2.3$ & 0.116 & 0.09 \\
\hline Somatizasyon & $0.44 \pm 0.60$ & $0.42 \pm 0.53$ & 0.852 & 0.03 \\
\hline Obsesif-kompulsif belirtiler & $0.78 \pm 0.59$ & $0.68 \pm 0.64$ & $\mathbf{0 . 0 4 9}$ & 0.16 \\
\hline Kişiler arası duyarlılık & $0.6 \pm 0.6$ & $0.5 \pm 0.6$ & 0.078 & 0.16 \\
\hline Depresyon & $0.58 \pm 0.63$ & $0.51 \pm 0.61$ & 0.280 & 0.11 \\
\hline Anksiyete & $0.53 \pm 0.52$ & $0.5 \pm 0.59$ & 0.629 & 0.05 \\
\hline Hostilite & $0.67 \pm 0.76$ & $0.58 \pm 0.62$ & 0.108 & 0.12 \\
\hline Fobik anksiyete & $0.35 \pm 0.41$ & $0.3 \pm 0.42$ & 0.188 & 0.12 \\
\hline Paranoid düşünce & $0.69 \pm 0.63$ & $0.56 \pm 0.6$ & $\mathbf{0 . 0 1 2}$ & 0.21 \\
\hline Psikotizm & $0.45 \pm 0.53$ & $0.4 \pm 0.48$ & 0.257 & 0.09 \\
\hline Ek maddeler & $0.61 \pm 0.67$ & $0.5 \pm 0.6$ & 0.059 & 0.17 \\
\hline Rahatsılık Ciddiyeti & $0.11 \pm 0.09$ & $0.1 \pm 0.09$ & $\mathbf{0 . 0 1 3}$ & 0.11 \\
\hline Belirti Toplamı & $19.14 \pm 12.6$ & $17.5 \pm 13.6$ & 0.102 & 0.12 \\
\hline Semptom rahatsızlık indeksi & $0.30 \pm 0.20$ & $0.24 \pm 0.1$ & $\mathbf{0 . 0 1 2}$ & 0.37 \\
\hline Ort \pm (SS): Ortalama \pm (Standart Sapma), $\mathrm{t}$ testi, paired t testi, Wilcoxon testi, etki büyüklüğü analizi & & \\
\hline
\end{tabular}


Sakarya Tip Dergisi 2021;11(2):337-346

KARTAL ve Ark., Orucun Ruh Sağlığı Üzerine Etkileri

Tablo 3: Cinsiyete göre Ramazan Öncesi ve Ramazan Sonrası GSA ve KSE’den elde edilen puanların Kesme Değerine Göre Dağılımı ve Oranı

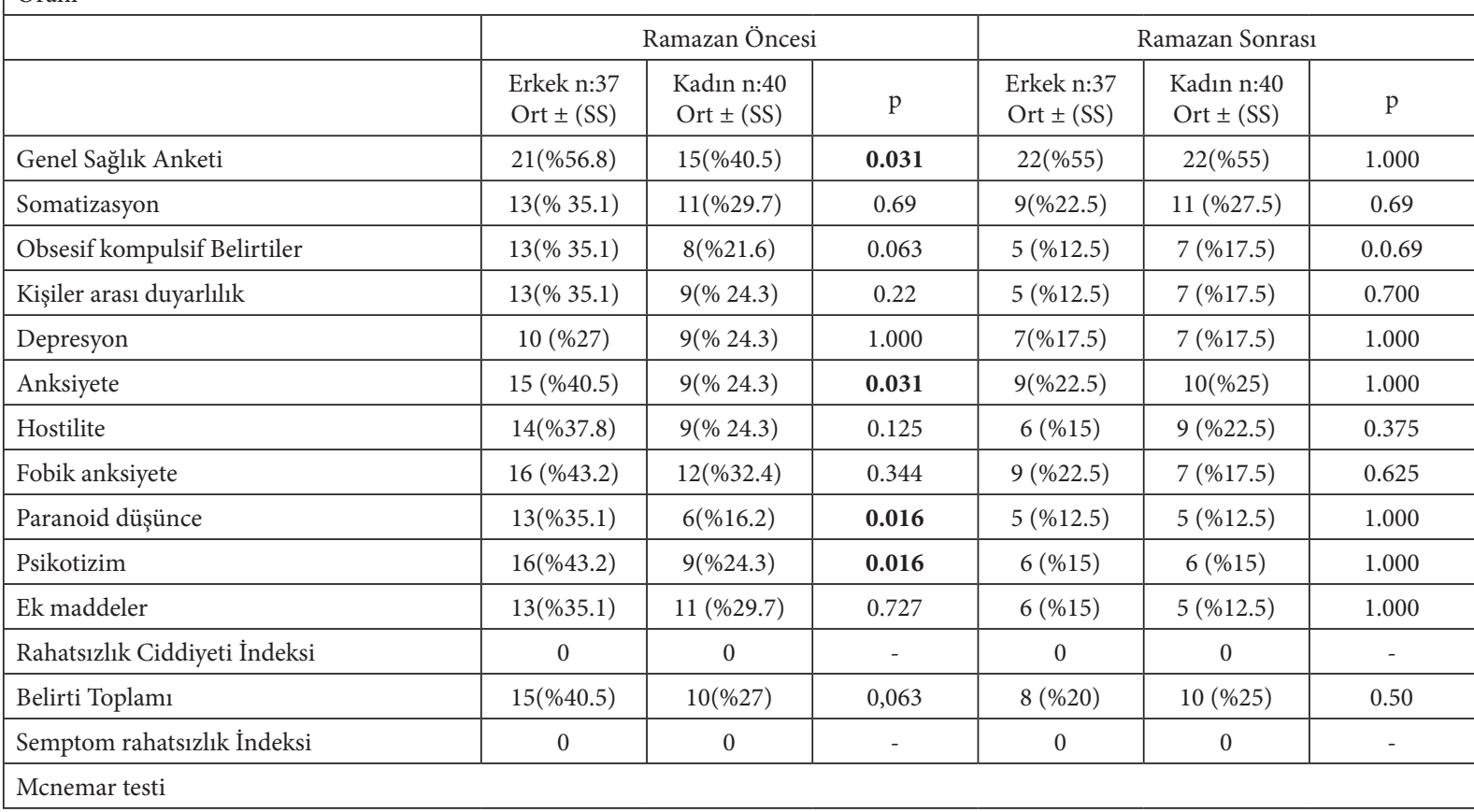

Tablo 4: Ramazan Öncesi ve Ramazan Sonrası Cinsiyetler arası GSA ve KSE ortalama Puanlarının Karşılaştırması

\begin{tabular}{|c|c|c|c|c|c|c|}
\hline & \multicolumn{3}{|c|}{ Ramazan Öncesi } & \multicolumn{3}{|c|}{ Ramazan Sonrası } \\
\hline & $\begin{array}{l}\text { Erkek n:37 } \\
\text { Ort } \pm(\text { SS) }\end{array}$ & $\begin{array}{c}\text { Kadin n:40 } \\
\text { Ort } \pm(\text { SS) }\end{array}$ & $\mathrm{p}$ & $\begin{array}{l}\text { Erkek n:37 } \\
\text { Ort } \pm(S S)\end{array}$ & $\begin{array}{c}\text { Kadın n:40 } \\
\text { Ort } \pm(S S)\end{array}$ & $\mathrm{p}$ \\
\hline Genel Sağlık Anketi & $2.02 \pm 2.02$ & $1.5 \pm 2.31$ & 0.304 & $1.19 \pm 1.74$ & $1.92 \pm 2.67$ & 0.058 \\
\hline Somatizasyon & $0.53 \pm 0.69$ & $0.36 \pm 0.48$ & 0.074 & $0.42 \pm 0.55$ & $0.43 \pm 0.51$ & 0.566 \\
\hline Obsesif kompulsif belirtiler & $0.9 \pm 0.64$ & $0.66 \pm 0.50$ & 0.050 & $0.65 \pm 0.61$ & $0.69 \pm 0.67$ & 0.815 \\
\hline Kişiler arası duyarlılık & $0.78 \pm 0.68$ & $0.41 \pm 0.48$ & 0.005 & $0.59 \pm 0.69$ & $0.41 \pm 0.51$ & 0.09 \\
\hline Depresyon & $0.69 \pm 0.74$ & $0.49 \pm 0.51$ & 0.193 & $0.55 \pm 0.63$ & $0.48 \pm 0.59$ & 0.518 \\
\hline Anksiyete & $0.63 \pm 0.55$ & $0.43 \pm 0.48$ & 0.116 & $0.53 \pm 0.65$ & $0.46 \pm 0.53$ & 0.274 \\
\hline Hostilite & $0.91 \pm 0.91$ & $0.45 \pm 0.50$ & 0.008 & $0.64 \pm 0.65$ & $0.52 \pm 0.60$ & 0.938 \\
\hline Fobik anksiyete & $0.46 \pm 0.48$ & $0.24 \pm 0.31$ & 0.012 & $0.42 \pm 0.52$ & $0.20 \pm 0.23$ & 0.009 \\
\hline Paranoid düşünce & $0.81 \pm 0.72$ & $0.57 \pm 0.52$ & 0.021 & $0.64 \pm 0.65$ & $0.50 \pm 0.53$ & 0.614 \\
\hline Psikotizm & $0.59 \pm 0.61$ & $0.32 \pm 0.41$ & 0.002 & $0.47 \pm 0.49$ & $0.33 \pm 0.46$ & 0.445 \\
\hline Ek maddeler & $0.75 \pm 0.73$ & $0.48 \pm 0.60$ & 0.033 & $0.61 \pm 0.67$ & $0.39 \pm 0.52$ & 0.042 \\
\hline Rahatsızlık Ciddiyeti & $0.133 \pm 0.1$ & $0.082 \pm 0.07$ & 0.01 & $0.11 \pm 0.1$ & $0.08 \pm 0.09$ & 0.434 \\
\hline Belirti Toplamı & $22.57 \pm 12.88$ & $15.98 \pm 11.63$ & 0.42 & $18.83 \pm 14.67$ & $16.62 \pm 12.62$ & 0.196 \\
\hline Semptom rahatsızlık indeksi & $0.3 \pm 0.12$ & $0.29 \pm 0.25$ & 0.1790 & $0.26 \pm 0.11$ & $0.22 \pm 0.09$ & 0.502 \\
\hline
\end{tabular}


Sakarya Tip Dergisi 2021;11(2):337-346

KARTAL ve Ark., Orucun Ruh Sağlığı Ưzerine Etkileri

Tablo 5: Cinsiyete Göre Ramazan Öncesi ve Ramazan Sonrası GSA ve KSE ortalama puanları ve değişim

\begin{tabular}{|l|c|c|c|c|c|c|c|c|}
\hline & \multicolumn{3}{|c|}{ Erkek n:37 } & \multicolumn{3}{c|}{ Kadın n:40 } \\
\hline & $\begin{array}{c}\text { Öncesi } \\
\text { Ort } \pm(\mathrm{SS})\end{array}$ & $\begin{array}{c}\text { Sonrası } \\
\text { Ort } \pm(\mathrm{SS})\end{array}$ & $\mathrm{p}$ & E.S.(d) & $\begin{array}{c}\text { Öncesi } \\
\text { Ort } \pm(\mathrm{SS})\end{array}$ & $\begin{array}{c}\text { Sonras } \\
\text { Ort } \pm(\mathrm{SS})\end{array}$ & $\mathrm{p}$ & E.S.(d) \\
\hline Genel Sağlık Anketi & $2.02 \pm 2.02$ & $1.19 \pm 1.74$ & $\mathbf{0 . 0 0 2}$ & 0.39 & $1.5 \pm 2.31$ & $1.92 \pm 2.67$ & 0.5 & 0.16 \\
\hline Somatizasyon & $0.53 \pm 0.69$ & $0.42 \pm 0.55$ & 0.157 & 0.17 & $0.36 \pm 0.48$ & $0.43 \pm 0.51$ & 0.2 & 0.14 \\
\hline Obsesif Kompulsif Belirtiler & $0.9 \pm 0.64$ & $0.65 \pm 0.61$ & $\mathbf{0 . 0 0 1}$ & 0.39 & $0.66 \pm 0.50$ & $0.69 \pm 0.67$ & 0.722 & 0.05 \\
\hline Kişiler arası duyarlılık & $0.78 \pm 0.68$ & $0.59 \pm 0.69$ & $\mathbf{0 . 0 3 3}$ & 0.27 & $0.41 \pm 0.48$ & $0.41 \pm 0.51$ & 0.700 & 0.00 \\
\hline Depresyon & $0.69 \pm 0.74$ & $0.55 \pm 0.63$ & 0.115 & 0.20 & $0.49 \pm 0.51$ & $0.48 \pm 0.59$ & 0.915 & 0.01 \\
\hline Anksiyete & $0.63 \pm 0.55$ & $0.53 \pm 0.65$ & 0.223 & 0.16 & $0.43 \pm 0.48$ & $0.46 \pm 0.53$ & 0.443 & 0.05 \\
\hline Hostilite & $0.91 \pm 0.91$ & $0.64 \pm 0.65$ & 0.200 & 0.341 & $0.45 \pm 0.50$ & $0.52 \pm 0.60$ & 0.326 & 0.126 \\
\hline Fobik anksiyete & $0.46 \pm 0.48$ & $0.42 \pm 0.52$ & 0.722 & 0.07 & $0.24 \pm 0.31$ & $0.20 \pm 0.23$ & 0.340 & 0.14 \\
\hline Paranoid düşünce & $0.81 \pm 0.72$ & $0.64 \pm 0.65$ & $\mathbf{0 . 0 4 5}$ & 0.24 & $0.57 \pm 0.52$ & $0.50 \pm 0.53$ & 0.108 & 0.13 \\
\hline Psikotizim & $0.59 \pm 0.61$ & $0.47 \pm 0.49$ & 0.107 & 0.21 & $0.32 \pm 0.41$ & $0.33 \pm 0.46$ & 0.818 & 0.02 \\
\hline Ek maddeler & $0.75 \pm 0.73$ & $0.61 \pm 0.67$ & 0.114 & 0.19 & $0.48 \pm 0.60$ & $0.39 \pm 0.52$ & 0.300 & 0.16 \\
\hline Rahatsızlık Ciddiyeti İndeksi & $0.133 \pm 0.1$ & $0.11 \pm 0.1$ & $\mathbf{0 . 0 0 5}$ & 0.23 & $0.083 \pm 0.07$ & $0.083 \pm 0.085$ & 0.502 & 0.00 \\
\hline Belirti Toplamı & $22.57 \pm 12.88$ & $18.83 \pm 14.67$ & $\mathbf{0 . 0 1 6}$ & 0.27 & $15.98 \pm 11.63$ & $16.62 \pm 12.62$ & 0.956 & 0.05 \\
\hline Semptom rahatsızlık indeksi & $0.3 \pm 0.12$ & $0.26 \pm 0.11$ & $\mathbf{0 . 0 1 4}$ & 0.34 & $0.29 \pm 0.25$ & $0.22 \pm 0.09$ & 0.361 & 0.37 \\
\hline paired t testi, Wilcoxon testi, etki büyüklüğü analizi & & & & & \\
\hline
\end{tabular}

\section{TARTIŞMA}

Çalışmamızda genç erişkin sağlık çalışanlarında Ramazan ayından bir hafta önce ve bir hafta sonrasında depresif belirti ve genel psikiyatrik semptomlar değerlendirildi. Çalışmaya dahil edilen tüm katılımcılarda Ramazan ayından bir hafta sonra paranoid düşünce ve psikotizm sıklığında, obsesif kompulsif belirti ve paranoid düşünce düzeyinde anlamlı azalma olduğu, ramazan orucunun paranoid düşüncenin azalmasına etkisinin küçük boyutta olduğu saptanmıştır. Ayrıca katılımcıların var olduğunu algıladıkları psikiyatrik belirtilerden duydukları sıkıntının ağırlıklı ortalama puanlarına Ramazan orucunun etkisinin küçük düzeyde olduğu ve belirtilerinden duydukları sıkıntıda anlamlı azalma olduğu bulunmuştur, Orucun psikolojik duruma etkisi ile ilişkili olarak, dışsal ödüllerden bireyin kendi isteği ile feragat etmesinin zihinsel uyanıklık, sakinlik duygusu, ruh sağlığında iyilik haline katkı sağladığ 1 varsayımında bulunulmaktadır. ${ }^{11}$ Filogenetik açıdan oruç tutma sırasındaki ruhsal iyilik halinin hayatta kalmak ve besin aramak için uyarlanabilir bir mekanizmayı temsil edebileceği düşünülmektedir. ${ }^{11}$ Böylelikle aşırı beslenme- nin aksine, oruçla birlikte, kıtlıkla başa çıkmak üzere devreye giren adaptif mekanizmalar insanda fiziksel ve ruhsal belirtilerde iyileşmeye neden olabilir. ${ }^{11}$ Genelde toplumun genç erişkin kesiminde yapılan ve çalışmamıza benzer çalışma desenlerinde Ramazan ayı öncesinde ve sonrasında genel psikiyatrik belirtilerin değerlendirildiği ölçekler kullanılarak yapılan (örneğin GSA, SCL-90 gibi) gözlemsel çalışmalarda ramazan orucunun ruh sağlığı üzerine olumsuz etkisinin olmadığı veya olumlu etkisinin olabileceği bildirilmiştir. ${ }^{20-25}$

Araştırmamızın en önemli bulgusu Ramazan öncesi kadınlara kıyasla erkek katılımcıların obsesif kompulsif belirtiler, kişiler arası duyarlılık, hostilite, fobik anksiyete, paranoid düşünce ve psikotizm seviyesinin anlamlı düzeyde yüksek tespit edilmesi ve Ramazan ayı sonrasında ise kişiler arası ilişkiler, hostilite, paranoid düşünce ve psikotizm düzeyinde erkek ve kadın cinsiyet açısından anlamlı farklılık saptanmamış olmasıdır. Erkek katılımcılarda Ramazan öncesinde sonrasına göre depresyon, anksiyete, paranoid düşünce, psikotizm semptomlarında azalma gözlenirken, 
kadın katılımcılarda psikiyatrik belirtilerde anlamlı farklılık olmadığı saptanmıştır. Ayrıca erkeklerde belirtilerden duyulan sıkıntı, algıladıkları belirti çeşitliği ve algıladıkları belirtilerinden duydukları sıkıntının ağırlıklı ortalamasını yansıtan KSE global ölçek puanlarında da azalma gözlemlenmiştir. Ramazan’ın erkeklerdeki azalan belirtilere etkisinin küçük düzeyde olduğu tespit edilmiştir. Özetle çalışmamzıda Ramazan orucundan sonra kadınlarda ruh sağlı̆̆ lerde bazı psikiyatrik belirtilerde iyileşme olduğu tespit edilmiştir. Shafi ve ark'nın yürüttügü bir araştırmada, ruh sağlığı üzerine ramazan orucunun erkeklerde daha fazla iyileştirici özellik gösterdiği gözlemlenmiş ancak araştırmaya alınan katılımcıların çoğunu kadınlar oluşturduğu için istatistiksel anlamlılık değerlendirilmemiştir. ${ }^{25}$ Sağlıklı bir örneklemde belirlediğimiz grupta cinsiyetler arası ruhsal belirtilerdeki bu farklılık öncelikle cinsiyet rollerinin evrimsel süreci ile ilişkilendirilebilir. İlk çağlarda rekabeti ve fiziksel olarak güçlü olmayı gerektiren besin arama davranışı erkeğin üstlendiği bir görevdi. ${ }^{26}$ Dolayısıyla kişiler arası duyarlılık, hostilite, paranoid düşünce, psikotizm gibi toplumsal risk ve tehlikelerle ilişkilendirilebilecek belirtilerin erkeklerde daha yüksek saptanması üstlenilen cinsiyet rollerinin sonucu ile ilişkili olarak gelișen adaptasyona bağlı olabilir ve orucun erkeklerde sosyal ilişkilerde iyileşme üzerinden toplumsal açıdan olumlu sonuçlar yaratabileceği çıkarımı yapılabilir. Ramazan ayında erkek katılımcılar ile yapılan çalışmaları incelediğimizde; bir çalışmada 12 sağlıklı erkek katılımcı Ramazan ayından bir hafta öncesinde ve Ramazan ayından iki hafta sonra değerlendirilmiş ve ramazan orucunun bilişsel fonksiyonlar üzerine koruyucu etkisinin olduğu gösterilmiştir. ${ }^{27} 14$ sağlıklı erkeğin ramazan ayından 10 gün önce, Ramazan ayının son 10 gününde ve Ramazan ayından 20 gün sonra incelendiği bir çalışmada da yorgunluk ve zihinsel stresin ramazan orucu ile olumsuz olarak etkilenmediği sonucuna ulaşılmıştır. ${ }^{29}$ Almanya'da sağlıklı erkek katılımcıların değerlendirildiği çalışmada da Ramazan ayı ortasından itibaren Ramazan ayı sonuna doğru duygu durum ve yorgunlukta iyileşme olduğu gözlemlenmiştir. Ramazan oru- cunun ruh hali, yorgunluk ve sağlıkla ilgili yaşam kalitesi açısından faydalar sağlayabileceği bildirilmiştir. ${ }^{29}$ Ramazan orucu ile kadınların ruhsal durumunu değerlendiren çalışmalara bakıldığında bir çalışmada ramazan orucunun kadınlarda subjektif iyilik halinde azalmayı da kapsayan yorgunluğu arttırdığı, genç kadın atletlerin dahil edildiği başka bir çalışmada ise ramazan orucu sırasında bilişsel işlevlerin olumsuz etkilenmediği bildirilmiştir., ${ }^{3,30} \mathrm{Biz}$ de çalışmamızda oruç tutan sağlıklı kadın katılımcılarda Ramazan ayından bir hafta sonrasında ruhsal belirtilerde anlamlı fark oluşturacak düzeyde bir etki gözlemlemedik. Kadınların erkeklere göre gebelik, emzirme gibi fizyolojik zorluklarla karşı karşıya kaldığ 1 ve stresör faktörlere karş1 ek fizyolojik adaptasyonlar gösterdiği bilinmektedir. Bir araştırmada kadınların erkeklere oranla daha düşük oranda açlıktan, daha yüksek oranda tokluktan etkilendiği bildirilmiştir. Bu durumun yeme davranışını kontrol eden hipotalamustaki alanlar ve iştah düzenlemesini etkileyen estradiol gibi seks hormonlarının konsantrasyonundaki farktan kaynaklandığı düşünülmektedir. ${ }^{31}$ Ayrıca oruç ile ilişkili yapılan bir Difüzyon Tensor Görüntüleme çalışmasında en az 3 hafta süreli orucun ardından beyinde mikro-yapısal değişiklikler ortaya çıktığı belirlenmiştir. ${ }^{32}$ İslami kurallara göre kadınların menstruasyon döneminde oruç tutmuyor olması da fizyolojik olarak strese adaptasyon sürecinde aksama yaratabilir. Bu bilgiler doğrultusunda erkeklerin oruç tutarak adaptasyon mekanizmalarından daha fazla etkilendiği çıkarımı yapılabilir. Strese yanıt da cinsiyetler açısından farklı fizyolojik yanıtlarının olduğu temeli ile çalışmamızın sonuçları uyuşmakla birlikte, orucun iyileștirici etkilerinin aslında bedensel olarak bir adaptasyon sürecini kapsadığı bu yüzden ruh sağlığına olumlu etkilerin ortaya çıkışının bu sürecin sonunda gözlemlenebileceğini varsayabiliriz.

Çalışmamızın kısıtllılıkları arasında Ramazan ayı içinde ruhsal bulguları değerlendirmemiş olmamız ve oruç tutmayan kontrol grubunun çalışmaya dahil edilmemesi yer alabilir. Besin kısıtlamasına yanıt olarak fizyolojik değişim sonrası ruhsal belirtilerdeki değişimi değerlendirirken ek 
bedensel veya hormonal değişimleri takip etmemiş olmamız da kısıtlılıklarımız arasındadır. Son olarak Ramazan orucu sadece yemenin kontrolü değil, zihinsel kontrolü de içeren bir ibadettir. ${ }^{21}$ Yeme kontrolünde prefrontal korteksin de dahil olduğu göz önüne alındığında33, katılımcıların din ile ilişkili bilişlerinin ve diğer ritüellerinin de sonuçlarımıza aracılık edip etmediğinin incelenmemiş olması kısıtlılıklarımızdandır.

\section{SONUÇ}

Çalışmamızın sonuçları sağlıklı erişkinlerde Ramazan orucunun psikiyatrik semptomlara olumsuz etki göstermediğini ve erkek katılımcılarda ruh sağlı̆̆ını iyileştirici etkilerinin olabileceğini desteklemektedir. ${ }^{11}$ Fizyolojik bir stres etkeni olarak Ramazan orucunun ruhsal ve bedensel savunma mekanizmalarını harekete geçirerek organizmanın dayanıklılığını arttırdığı ve ruh sağlığı üzerine olumlu etkilerde bulunduğu söylenebilir.

Araştırmamızın etik kurul onayı T.C İnönü Üniversitesi Bilimsel Araştırma ve Yayın Etiği Kurulu'nun 30.07.2019 tarihli oturumundan, 2019/246 araştırma protokol numarası ile alınmıştır. 
Sakarya Tip Dergisi 2021;11(2):337-346

KARTAL ve Ark., Orucun Ruh Sağlığı Üzerine Etkileri

\section{Kaynaklar}

1. Șentürk L, Yazıcı S. Diyanet İslam İlmihali, 7.baskı, Ankara: Diyanet İșleri Bașkanlı̆̆ı: 2000. s:240.

2. Karaağaoğlu N, Yücecan S. Oruç Tutan Bireylerin Ramazan'da ve Ramazan Bayraminda Besin Tüketim Durumlar. Beslenme ve Diyet Dergisi 1999; 28: 29-38.

3. Ovayolu Ö, Ovayolu N, Taşan E. Does Ramadan fasting affect fatigue in nurses?. Holis Nurs Pract 2016; 30:222-226.

4. Erdem $O$. The investigation of the effects of Ramadan fasting on the mood state of healthy volunteer persons. Family Practice and Palliative Care 2018; 3:1-6.

5. Beshyah SA, Hajjaji IM, Ibrahim WH, et al. The year in Ramadan fasting research (2017): a narrative review. Ibnosina J Med Biomed Sci 2018; 10:39-53.

6. Chehovich C, Demler TL, Leppien E. Impact of Ramadan fasting on medical and psychiatric health. Int Clin Psychopharmacol 2019; 34:317-322.

7. Mattson MP, Longo VD, Harvie M. Impact of intermittent fasting on health and disease processes. Ageing Res Rev 2017; 39:46-58.

8. Cherif A, Roelands B, Meeusen R, Chamari K. (2016). Effects of intermittent fasting, caloric restriction, and Ramadan intermittent fasting on cognitive performance at rest and during exercise in adults. Sports Med 2016; 46: 35-47.

9. Mager DE, Wan R, Brown M, Cheng A, Wareski P, Abernethy DR, Mattson MP. Caloric restriction and intermittent fasting alter spectral measures of heart rate and blood pressure variability in rats. FASEB J 2006; 20:631-637.

10. Halagappa VKM, Guo Z, Pearson $M$ et al. Intermittent fasting and caloric restriction ameliorate age-related behavioral deficits in the triple-transgenic mouse model of Alzheimer's disease. Neurobiol Dis 2007; 26: 212-220.

11. Fond G, Macgregor A, Leboyer M, Michalsen A. Fasting in mood disorders: neurobiology and effectiveness. A review of the literature. Psychiatry Res 2013; 209: 253-258.

12. Shojaie M, Ghanbari F, Shojaie N. Intermittent fasting could ameliorate cognitive function against distress by regulation of inflammatory response pathway. J Adv Res 2017; 8:697-701.

13. Nikolai S, Pallauf $K$, Huebbe P, Rimbach G. Energy restriction and potential energy restriction mimetics. Nutr Res Rev 2015;28:100-120.

14. Martin B, Mattson MP, Maudsley S. Caloric restriction and intermittent fasting: two potential diets for successful brain aging. Ageing Res Rev 2006; 5: 332-353.

15. American Psychiatric Association. Diagnostic and statistical manual of mental disorders (DSM-5 ). American Psychiatric Pub: 2013.

16. Goldberg DP. The detection of psychiatric illness by questionnaire. Maudsley monograph 1972; 21.

17. Kıllç C. Genel Sağlık Anketi: Geçerlik ve güvenirlik çalışması. Turk Psikiyatri Derg 1996; 7:3-11.

18. Derogatis LR. The Brief Symptom Inventory (BSI): Administration, scoring and procedures manual. Minneapolis, MN, National Computer System, 1993.
19. Sahin, N, Durak A. Kisa Semptom Envanteri (Brief Symptom Invetory-BSI): Turk Gencleri Icin Uyarlanmasi. Türk Psikoloji Dergisi 1994.

20. Kazemi M, Karimi S I M A, Ansari A, Negahban T, Hosseini S H, Vazirinejad R. The Effect of Ramadan Fasting on Psychological Health and Depression in Sirjan Azad University Students. Journal of Rafsanjan University of Medical Sciences 2006; 5:117-122.

21. Gilavand A, Fatahiasl J. Studying effect of fasting during Ramadan on mental health of university students in Iran: A review. J Res Med Dent Sci 2018; 6: 205-9.

22. Javanbakht M, Ziaee SA, Homam SM, Rahnama A. Effect of Ramadan Fasting on Self-Esteem and Mental Health of Students. The Quarterly Journal of Fundamentals of Mental Health 2010; 11: 266-73.

23. Moghadamnia M, Maghsoudi SH. A survey of effects of fasting in Ramadan on the level of stress. Journal Of Guilan University Of Medical Sciences 2004; 3: 54-60.

24. Nikfarjam M, Noormohammadi MR, Mardanpour Shahrekordi E, Esmaeili Vardanjani $S$ A, HasanPour-Dehkordi, A. The effect of fasting on emotional intelligence in clergies in Shahrekord seminary. Journal of Shahrekord Uuniversity of Medical Sciences 2013;15.

25. Shafie N, Allahtavakoli M, Rafati F, Kazemi MAJID. Effect of Ramadan Fasting on Mental Health of Nursing Students in Jiroft Nursing College. Journal of Rafsanjan University of Medical Sciences 2007; 6: 73-78.

26. Yllmaz S. Toplumsal Cinsiyet Rollerinin Günlük Hayattaki Yansımaları: Çorum/Alaca Örneği. İmgelem 2018; 2:59-79.

27. Iqbal M, Jamea AA, Alonso-Alonso M, Al-Regaiey KA, Bashir S. Cortical thickness, neurocognitive, and body composition effects of fasting during Ramadan. J Res Med Sci 2019; 24.

28. Boukhris $O$, Trabelsi $K$, Shephard RJ, et al. Sleep patterns, alertness, dietary intake, muscle soreness, fatigue, and mental stress recorded before, during and after Ramadan observance. Sports 2019; 7: 118.

29. Nugraha B, Ghashang SK, Hamdan I, Gutenbrunner C. Effect of Ramadan fasting on fatigue, mood, sleepiness, and health-related quality of life of healthy young men in summer time in Germany: A prospective controlled study. Appetite 2017; 111:38-45.

30. Ghayour Najafabadi M, Rahbar Nikoukar L, Memari A, Ekhtiari H, Beygi S. Does ramadan fasting adversely affect cognitive function in young females?. Scientifica 2015; 2015.

31. Steyn FJ, Tolle V, Chen C, Epelbaum J. Neuroendocrine regulation of growth hormone secretion. Comprehensive Physiology 2011; 6: 687-735.

32. De Lauzon B, Romon M, Deschamps V et al. The Fleurbaix Laventie Ville Sante (FLVS) study group: the three-factor eating questionnaire-R18 is able to distinguish among different eating patterns in a general population. J. Nutr 2004; 2380: 2372-2004.

33. Del Parigi ANGELO, Gautier JF, Chen K et al. Neuroimaging and obesity: mapping the brain responses to hunger and satiation in humans using positron emission tomography. Ann N Y Acad Sci 2002; 967:389-397. 